\title{
Pengembangan Handle Rem Sepeda Motor Berbahan Limbah Plastik Hasil Cetakan S 45c
}

\section{Development Of Motorcycle Brake Handle Made From Plastic Waste Molding Product With Material Steel S 45c}

\author{
Irawan Satriadyanto ${ }^{1}$, Pasek Nugraha ${ }^{2}$, Rihendra Dantes ${ }^{3}$
}

\begin{abstract}
1, Program Studi Pend. Teknik Mesin Universitas Pendidikan Ganesha, Singaraja, Indonesia 2,Program Studi Pend. Teknik Mesin Universitas Pendidikan Ganesha, Singaraja, Indonesia 3,Program Studi Pend. Teknik Mesin Universitas Pendidikan Ganesha, Singaraja, Indonesia

e-mail: \{1rawalepeltier97@gmail.com, paseknugraha@undiksha.ac.id, rihendradantes@undiksha.ac.id\}
\end{abstract}

\begin{abstract}
Abstrak
Perkembangan teknologi banyak menimbulkan dampak positif dan negatif. Adanya material baru yang biasanya digunakan oleh aktifitas manusia, termoplastik merupakan salah satu bentuk material baru. Salah satu bahan termoplastik adalah plastik yang biasa kita gunakan untuk aktifitas sehari-hari.Yang akan dibahas bagaimana rancangan handle rem berbahan limbah plastik dan bagaimana proses pembuatan handle rem berbahan limbah plastik. pengecoran adalah suatu proses penuangan material cair seperti logam dan plastik yang dimasukan kedalam cetakan dan jenis-jenis cetakan tersebut berupa cetakan grafit, cetakan pasir, cetakan permanen, cetakan keramik, cetakan plaster dan cetakan shell Pada proses pembuatan handle ini peneliti hanya mengambil 5 jenis plastik sebagai bahan dasar yang akan digunakan untuk pembuatan handle rem, yaitu jenis Polyethylene Terephthalate (PET/PETE), High Density Polyethylene (HDPE), Low Density Polyethylene (LDPE), Polypropylene $(P P)$, Polystyrene (PS). Sebelum memulai penelitian ini melakukan proses pemisahan material plastik yang sudah dikumpulkan berdasarkan jenisnya. Pada proses pengecoran handle rem penelitian ini mengkombinasikan beberapa jenis plastik anatara lain jenis PET dengan LDPE, PET dengan PP, PET dengan PS, dan PP dengan HDPE. berdasarkan hasil visualitas perbandingan campuran limbah plastik yang digunakan untuk pembuatan handle rem bahan limbah plastik dengan jenis PP dan HDPE merupakan hasil cetakan yang baik. Karena dari awal pengerjaan hingga akhir tidak mengalami kendala yang begitu berat untuk proses pengerjaan handle rem. Pada saat proses pelepasannya handle sangat mudah dan tidak memerlukan waktu yang lama.

Kata Kunci: Daur ulang limbah plastik, pengecoran limbah plastik, handle rem limbah plastik Abstract

Many technological developments have positive and negative impacts. The existence of new materials that are usually used by human activities, thermoplastic is one form of new material. One of the thermoplastic materials is plastic which we usually use for daily activities. Because too much use of this plastic is a problem in itself, one of which is difficult to decompose naturally. Because plastic has researchers interested in conducting development research entitled the development of motorcycle brake handles made from plastic waste. In the process of making this handle researchers only take 5 types of plastic as a basic material that will be used to manufacture brake handles, namely types of Polyethylene Terephthalate (PET / PETE), High Density Polyethylene (HDPE), Low Density Polyethylene (LDPE),
\end{abstract}


Polypropylene (PP), Polystyrene (PS). Before starting this research, the process of separating plastic materials that have been collected by type. In the brake handle casting process this research combines several types of plastic between other types of PET with LDPE, PET with PP, PET with PS, and PP with HDPE. based on the results of the visuality of the comparison of the mixture of plastic waste that is used for manufacturing brake handles of plastic waste materials with the type of PP and HDPE is a good mold. Because from the beginning of the process until the end did not experience obstacles that are so heavy for the process of handling the brake handle. At the time of the release process the handle is very easy and does not require a long time.

Keywords: Recycling of palstic waste, plastic waste casting, plastic waste brake handle

\section{PENDAHULUAN}

Perkembangan teknologi yang begitu pesat sehingga manusia dapat menciptakan alat dan material baru untuk memudahkan manusia dalam melakukan aktifitas sehari-hari. Dampak negatif dari perkembangan teknologi yaitu adalah banyaknya material baru yang tidak ramah lingkungan. Salah satu contoh material baru tersebut adalah plastik.

Permasalahan yang ditemui dilapangan, bahan dasar untuk pembuatan plastik adalah polimer, tetapi tidak seluruh polimer adalah plastik. Plastik dapat di kelompokkan menjadi 2 golongan, yaitu plastik Thermoplast dan plastik thermoset. Plastik thermoplast adalah plastik yang dapat dicetak berulang-ulang dengan adanya panas. Yang termasuk plastik thermoplast antara lain yaitu PE, PP, PS, ABS, Nynlon, PET, BPT, Polyacetal (POM), PC dan lain-lain. Thermoset adalah plastik yang apabila telah mengalami kondisi tertentu tidak dapat dicetak kembali karena kandungan polimernya berbentuk jaringan tiga dimensi yang termasuk plastik Thermoset adalah : PU (Poly Urethene), UF (Urea Formaldehyde), MF (Melamine Formaldehyde), Polyester, epoksi dan lain-lain (Sifat dan Karakteristik Material Plastik dan Bahan Aditiff Iman Mujiarto, 2005).

Limbah plastik berikut ini merukan jenis plastik yang paling sering kita jumpai dalam kehidupan sehari-hari jenis plastik Polyethylene Terephthalate (PET atau PETE), High Density Polyethylene (HDPE), Low Density Polyethylene (LDPE), Polypropylene (PP), Polystyrene (PS).

Usaha yang dapat dilakukan untuk meminimalisir limbah plastik dileburkan dalam casting plastic sehingga menjadi lelehan yang dapat cetak menggunakan dies. Pada penelitian ini, produk yang akan dihasilkan dari bahan limbah plastik yaitu handle rem.

Pengecoran (Casting) adalah suatu proses penuangan material cair seperti logam atau plastik yang dimasukan kedalam cetakan, kemuadian dibiarkan membeku didalam cetakan tersebut, dan kemudian dikeluarkan atau dipecah-pecah untuk dijadikan komponen mesin.

Klasifikasi yang berkaitan dengan bahan pembentukan dengan logam cair, dapat dikatagorikan sebagai berikut:

a) Expandable mold, yang mana tipe ini terbuat dari pasir, gips, keramik, dan bahan semacam itu dan umumnya dicampur dengan berbagai bahan pengikat (bonding agents) untuk peningkatan peralatan.

b) Permanent molds, yang mana terbuat dari logam yang tahan pada temperatur tinggi. cetakan ini digunakan berulang-ulang dan dirancang sedemikian rupa sehingga hasil cetakan dapat dihilangkan dengan mudah dan cetakan dapat digunakan untuk cetakan berikutnya. Cetakan logam dapat digunakan kembali karena bersifat konduktor dan lebih baik daripada cetakan bukan logam yang terbuang setelah digunakan. Sehingga, cetakan padat terkena tingkat yang lebih tingggi dari pendinginan, yang mempengaruhi struktur mikro dan ukuran butir dalam pengecoran.

c) Composite molds, yang mana terbuat dari dua atau lebih material yang berbeda (seperti pasir, grafit, dan logam) dengan menggabungkan keunggulan masing-masing bahan. 


\section{METODE}

Berdasarkan jenis limbah yang yang ada berikut ini adalah limbah plastik perpaduan yang akan digunakan sebagai bahan dasar untuk pembuatan handle rem

1. Polyethylene Terephthalate (PET atau PETE) + Low Density Polyethylene (LDPE).

2. Polyethylene Terephthalate (PET atau PETE) + Polypropylene (PP).

3. Polyethylene Terephthalate (PET atau PETE) + Polystyrene (PS).

4. Polypropylene (PP) + High Density Polyethylene (HDPE).

Limbah plastik adalah limbah plastik yang sering kita temui dalam kehidupan sehari-hari. Plastik adalah suatu polimer yang mempunyai sifat unik dan luar biasa. Polimer adalah suatu bahan yang terdiri dari unit molekul yang disebut monomer.

Tabel 1. Temperatur Leleh Maksimal Dari Sebuah Plastik

\begin{tabular}{|c|c|c|}
\hline \multicolumn{3}{|c|}{ Processing Leleh Proses Termoplastik } \\
\hline Material & ${ }^{\circ} \mathrm{C}$ & ${ }^{\circ} \mathrm{F}$ \\
\hline ABS & $180-240$ & $356-464$ \\
\hline Acetal & $185-225$ & $365-437$ \\
\hline Acrylic & $180-250$ & $356-482$ \\
\hline Nylon & $260-290$ & $500-554$ \\
\hline Poly Carbonat & $280-310$ & $536-590$ \\
\hline LDPE & $160-240$ & $320-464$ \\
\hline HDPE & $200-280$ & $392-536$ \\
\hline PP & $200-300$ & $392-572$ \\
\hline PS & $180-260$ & $356-500$ \\
\hline PVC & $160-180$ & $320-365$ \\
\hline
\end{tabular}

Desain yang akan digunakan pada handle rem mungkin hampir menyerupai bentuk semula, yang membedakan handle rem ini adalah warnanya saja, mungkin bisa lebih menarik. Karena bahan yang digunkan dari limbah plastik. Jadi hasil akhir dari handle rem tersebut sesuai dengan jenis warna dari plastik itu sendiri.

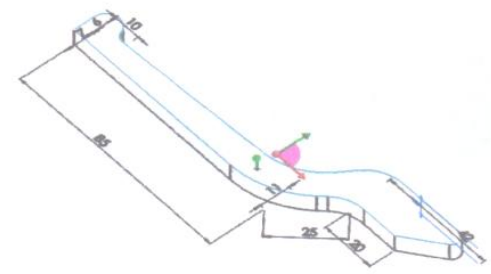

Gambar 1. Desaint Handle Rem

\section{Bahan Dasar Cetakan}

Cetakan yang akan digunakan dalam pembuatan produk ini adalah cetakan permanen (die casting). Bahan yang digunakan untuk membuat cetakan adalah S45C.

Baja JIS S45C Steel (JIS : Japanese Industrial Standard / Standar Industri Negara Jepang) atau equivalent AISI 1045 (AISI : American Iron and Steel Institute,standar Negara Amerika), atau DIN 1.1730 (DIN : Deutsches Institut für Normung/German institute for standardization, 
standar Negara Jerman), merupakan jenis baja "Medium Carbon Steel" (baja dengan kandungan unsur karbon medium : 0,3-0,5\% C).

Tahap selanjutnya adalah membuat cetakan yang akan digunakan untuk membuat handle rem berbahan limbah plastik. Cetakan yang akan digunakan untuk membuat Handle rem ini adalah cetakan permanen. Cara membuatnya kita menggunakan aplikasi CATIA. CATIA adalah suite perangkat lunak multi-platfrom untuk desaint pembuatan computer (CAD), Computer dibantu (CAM), setelah di desain hasil yang sudah selesai dipindahkan ke mesin CNC.

Dari Hasil Pengukuran pada anting handle rem gambaran yang akan dibuat adalah lengan handle rem sepeda motor beat selanjutnya akan digambarkan beserta ukuran dapat dilihat pada gambar 1.

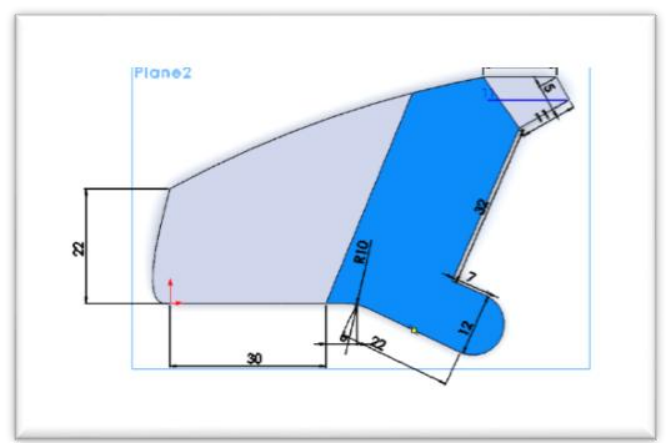

Gambar 2. Gambar Anting Handle Rem Motor

Tahap Pembuatan Handle berbahan dasar LDPE dan PET

Langkah yang dilakukan pertama timbang bahan dasar pembuatan Hamdle Rem. Langkah ke dua memberikan memberikan lapisan pada cetakan agar bahan tidak menempel pada cetaka. Langkah yang ke tiga leburkan plastik dengan kode LDPE dan PET secara bersamaan pada didalam wadah yang sudah disiapkan untuk mengecor. Langkah keempat setelah meleleh plastik tersebut masukkan delam cetakan yang sudah di buat. Langkah kelima setelah cairan yang berada di cetakan mengeras kuluarkan handle dari cetakan. Lakah keenam lakukan proses menghaluskan permukaan hasil pengecoran. Langkah ke tujuh pengeboran. Langkah ke delapan pemasangan anting dengan handle rem.

Tahap Pembuatan Handle berbahan dasar PET dan PP

Langkah yang dilakukan pertama timbang bahan dasar pembuatan Hamdle Rem. Langkah ke dua memberikan memberikan lapisan pada cetakan agar bahan tidak menempel pada cetaka. Langkah yang ke tiga leburkan plastik dengan kode PETE / PET dan PP secara bersamaan pada didalam wadah yang sudah disiapkan untuk mengecor. Langkah keempat setelah meleleh plastik tersebut masukkan delam cetakan yang sudah di buat. Langkah kelima setelah cairan yang berada di cetakan mengeras kuluarkan handle dari cetakan. Lakah keenam lakukan proses menghaluskan permukaan hasil pengecoran. Langkah ke tujuh pengeboran. Langkah ke delapan pemasangan anting dengan handle rem.

\section{Tahap Pembuatan Handle Berbahan Dasar PET dan PS}

Langkah yang dilakukan pertama timbang bahan dasar pembuatan Hamdle Rem. Langkah ke dua memberikan memberikan lapisan pada cetakan agar bahan tidak menempel pada cetaka. Langkah yang ke tiga leburkan plastik dengan kode PET dan PS secara 
bersamaan pada didalam wadah yang sudah disiapkan untuk mengecor. Langkah keempat setelah meleleh plastik tersebut masukkan delam cetakan yang sudah di buat. Langkah kelima setelah cairan yang berada di cetakan mengeras kuluarkan handle dari cetakan. Lakah keenam lakukan proses menghaluskan permukaan hasil pengecoran. Langkah ke tujuh pengeboran. Langkah ke delapan pemasangan anting dengan handle rem.

Tahap Pembuatan Handle Berbahan Dasar HDPE dan PP

Langkah yang dilakukan pertama timbang bahan dasar pembuatan Hamdle Rem. Langkah ke dua memberikan memberikan lapisan pada cetakan agar bahan tidak menempel pada cetaka. Langkah yang ke tiga leburkan plastik dengan kode HDPE dan PP secara bersamaan pada didalam wadah yang sudah disiapkan untuk mengecor. Langkah keempat setelah meleleh plastik tersebut masukkan delam cetakan yang sudah di buat. Langkah kelima setelah cairan yang berada di cetakan mengeras kuluarkan handle dari cetakan. Lakah keenam lakukan proses menghaluskan permukaan hasil pengecoran. Langkah ke tujuh pengeboran. Langkah ke delapan pemasangan anting dengan handle rem.

\section{HASIL DAN PEMBAHASAN}

Berikut ini merupakan hasil akhir dari proses pengecoran limbah plastik yang dicetakan menjadi handle rem.

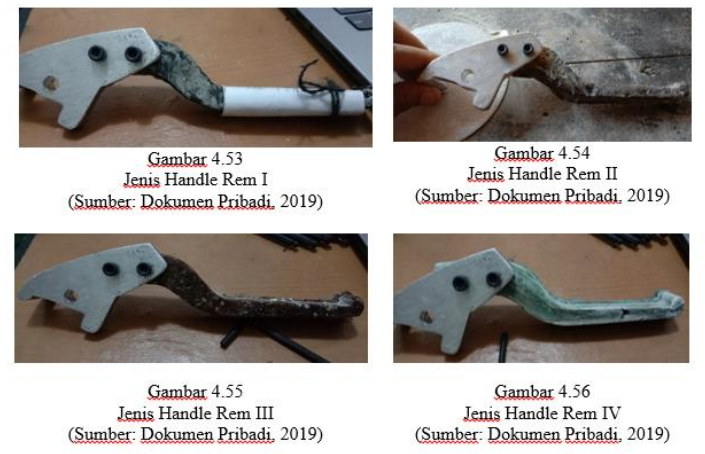

Gambar 3. Perbandingan Handle Rem Berbahan Limbah Plastik

Dari gambar diatas dapat dinilai bahwa jenis handle rem ke-IV merukapan hasil pengecoran limbah plastik terbaik dari segi visualitas dari jenis handle rem yang lainnya. Selain itu handle rem jenis ke-IV bahan dasarnya mudah didapat dan selama proses pengecoran juga sangat mudah dilakukan.

\section{KESIMPULAN DAN SARAN}

Berdasarkan dari hasil penelitian yang dilakukan dapat ditarik kesimpulan bahwa rancangan cetakan yang digunakan untuk membuat handle rem dari bahan limbah plastik dapat digunakan. Bahan yang digunakan untuk membuat cetakan tersebut adalah jenis S45C diamana jenis baja ini merupakan jenis baja karbon medium yang mengandung unsur karbon sekitar 0,3-0,5\% C.

Pada pengecoran yang dilakakukan adalah membuat handle rem. Jenis bahan yang digunakan untuk membuat handle rem adalah limbah plastik. limbah plastik yang digunakan dikombinasikan antara 2 jenis limbah plastik I Polyethylene Terephthalate (PET atau PETE) dengan Low Density Polyethylene (LDPE), II Polyethylene Terephthalate (PET atau PETE) dengan Polypropylene (PP), III Polyethylene Terephthalate (PET atau PETE) dengan Polystyrene (PS), IV Polypropylene (PP) dengan High Density Polyethylene (HDPE). 
Berdasarkan hasil visualitas pengecoran handle rem semua jenis kombinasi handle dari bahan limbah plastik I, II, III, IV masih terdapat beberapa void (cacat material) pada bagian handle yang sudah selesai.

Bedasarkan hasil visualitas keempat dari kombinasi limbah plastik jenis yang ke-IV yaitu jenis Polypropylene (PP) dengan High Density Polyethylene (HDPE) adalah jenis yang cukup baik digunakan untuk membuat handle rem karena dari awal pengerjaan hingga akhir tidak mengalami kendala yang begitu berat untuk proses pengerjaan handle rem.

Berdasarkan hasil penelitian ini dapat disarankan untuk kedepannya melakukan proses injection pada proses mencetak handle rem berikutnya dan lakukan juga proses pengujian pada material terutama melakukan uji ketangguhan ( uji impact) agar dapat mengetahui batas ketangguhan dari suatu material.

\section{UCAPAN TERIMA KASIH}

Tentunya dalam pelaksanaan penelitian ini penulis banyak sekali memperoleh bantuan dari berbagai pihak. Dalam kesempatan ini peneliti ingin mengucapkan rasa terima kasih serta penghargaan yang setingi - tingginya sebagai tanda syukur dan hormat peneliti kepada :

1. Prof. Dr. I Nyoman Jampel, M.P.d Selaku Rektor Universsitas Pendidikan Ganesha.

2. Dr. I Gede Sudirtha, S.P.d,,M.P.d selaku Dekan Fakultas Teknik dan Kejuruan.

3. Dr. Kadek Rihendra Dantes, S.T., M.T. selaku Ketua Jurusan Teknologi Industri dan dosen pembimbing II yang selalu memberikan arahan-arahan guna memotivasi penulis.

4. Dr. I Nyoman Pasek Nugraha S.T., M.T selaku Ketua Program Studi Pendidikan Teknik Mesin dan selaku dosen pembimbing I yang selalu mengayomi dengan sabar, memberikan tuntunan, dan bantuan, serta semangat selama penyusunan skripsi ini.

5. Staf dosen pengajar di program studi Pendidikan Teknik Mesin yang saya banggakan.

\section{DAFTAR RUJUKAN}

Febriansyah, 2019, "Inovasi Baru Mengubah Sampah Plastik Jadi Kertas yang Mudah Terurai". Tersedia pada https://tirto.id/inovasi-baru-mengubah-sampah-plastikjadi-kertas-yang-mudah-terurai-dftk (diakses tanggal 8 Juni 2019)

Khoirumansyah, 2012, "Macam-Macam Cetakan Logam". Tersedia pada http://khoirumansyahbtr.blogspot.com/2012/11/macam-macam-cetakanlogam.html (diakses tanggal 7 Juni 2019)

Logam Ceper, 2014, : "Cetakan Pasir (Sand Moulding)". Tersedia pada https://logamceper.com/cetakan-pasir-sand-moulding/ (diakses tanggal 7 Juni 2019)

Nurhenu Karuniastuti. Bahaya Plastik Terhadap Kesehatan Dan Lingkungan.

Prof. Drs. Soegyarto Mangkuatmodjo, maret 2014 "Stastik Lanjutan", Jakarta: PT Asdi Mahasatya.

Raggne, May 11, 2015, “Arti Kode Kemasan Plastik: PET(E), HDPE, PVC, LDPE, PP, PS" Tersedia pada https://raggne.wordpress.com/2015/05/11/arti-kode-kemasanplastik-pete-hdpe-pvc-ldpe-pp-ps/ (diakses tanggal 13 November 2018)

Samsudi, Fuad dan Yugohindra, 2011, Analisa Pengaruh Pengecoran Ulang Terhadap Sifat Mekanik Paduan Alumunium ADC 12.

STP Team , November 24, 2016, "Heat Treatment of Carbon Steel - S45C / C45 Steel". Tersedia pada https://www.steelindopersada.com/2016/11/heat-treatment-of-carbonsteel-aisi-s45c-steel-grades.html (diakses tanggal 7 Juni 2019)

sugiyono. (2010) Metode Penelitian Kuantitatif dan R\&D. Alfabeta. Bandung. 
Jurnal Pendidikan Teknik Mesin Undiksha

Vol.8 No. 1, Maret, 2020

p-ISSN: 2614-1876, e-ISSN: 2614-1884

Wikipedia, 30 November 2017, “Rem" tersedia pada https://id.wikipedia.org/wiki/Rem (diakses tanggal 13 November 2018) 